\title{
BILI: Building Information Literacy in Ireland
}

\author{
Amy Connolly, Lorraine Curran, Áine Lynch, Sile O'Shea
}

\begin{abstract}
Although information literacy (IL) practice has long been evident in Irish libraries, it was 2008 before the Working Group on Information Literacy (WGIL) published the first Irish national, cross-sector review. In 2012, we built on this research in order to (1) revisit the WGIL case studies and examine how IL was evolving, (2) consider the wider IL context in Ireland, and (3) examine innovations among international bodies supporting IL practice.

Nine international experts and seventeen Irish experts contributed to interviews and surveys. This article focuses on the Irish findings. Revisiting case studies demonstrated that IL remains a priority for the majority despite the economic recession. Wider themes uncovered include embedding IL in the curriculum and workplace, e-citizenship, continuing professional development and advocacy.

Recommendations centre on a two-tiered approach to IL development: a practitioner-led community of practice that facilitates communication and collaboration, and a high-level advocacy committee that fosters a holistic national strategy.
\end{abstract}

\section{Author}

Amy Connolly works as a Relief Library Assistant with Dublin City Library and Archive, Pearse Street 138- 144, Dublin 2.

Lorraine Curran works as a Parliamentary Assistant / Researcher at the Houses of the Oireachtas, Kildare Street, Dublin 2.

Email: lorcurran@gmail.com

Áine Lynch works as the Assistant Librarian at the Institute of Technology Blanchardstown, in Dublin.

Sile O'Shea works as an Assistant Librarian in the Honorable Society of King's Inns, Henrietta Street, Dublin. 


\section{Introduction}

As early as 1876 , Otis Robinson noted that "all that is taught in college amounts to very little, but if we can send students out self-reliant in their investigations, we will have accomplished much" (Abromeit \& Vaughan, 2004). IL terminology and pedagogy may have evolved, but the core importance of independent, lifelong learning has remained constant. In 2006, the Library Association of Ireland (LAI) formed the Working Group on Information Literacy (WGIL) to consider how to support IL development in Ireland. Their report, Review of Cross-sector Activity 2006 to 2008 and Initial Recommendations for Further Action, provided the first national, cross-sector review of Irish practice (O'Brien \& Russell, 2012). WGIL was succeeded by the Task Force on Information Literacy (TFIL) which sought to implement WGIL's recommendations. Aiming to help inform TFIL's actions, our research had three main objectives:

1. to revisit the case studies in the WGIL report and investigate how IL has evolved in Ireland since 2008;

2. to consider the wider context of IL in Ireland by gathering evidence of best practice and opinions on how TFIL could support practitioners;

3. to examine the initiatives of international organisations who support IL practitioners by gathering evidence of best practice and opinions on how TFIL could support practitioners.

For the purposes of this article, we will focus on the Irish findings.

The research was named BILI, or Building Information Literacy in Ireland. The reason for this was threefold. Firstly, IL is constantly evolving and it attracts practitioners who champion innovation and build on the work of others. Secondly, our research was a link in the chain of work pioneered by WGIL and TFIL. And finally, a key theme that emerged from our findings was the desire of library staff, both seasoned and new, to build on their own skills in order to deliver a better service. BILI reinforces the active nature of IL and IL providers in contemporary Ireland.

\section{Relevant literature}

The difficulty of defining information literacy is a core concern in the literature. Recognising this, WGIL reviewed prominent IL definitions and concluded that the CILIP definition is the most appropriate for Irish practitioners. The WGIL report also noted low levels of publication, inconsistent use of terminology and the lack of cross-sectoral cooperation (Working Group on Information Literacy, 2008). The international literature echoes this desire for national cohesion in approaching IL; for instance, the Danish National Library Authority (DNLA) sought to "define IL requirements at all levels, from kindergarten to $\mathrm{PhD}$ level" (Skov \& Skærbak 2003, 327) and the Finnish University Libraries launched "a national project to create an IL curriculum" (Kakkonen \& Virrankoski, 2010, 493). 
Much of the Irish literature focuses on higher education. Kavanagh $(2009,14)$ notes "the shift from library sessions that were largely independent of the academic courses... to fully integrated information literacy modules that are linked directly with projects assigned by academic colleagues" at Dublin Institute of Technology (DIT). Dunne (2008, 20) describes how, in Dublin City University, it is "becoming increasingly important to liaise with colleagues from across the university... to ensure that delivery of information literacy sessions is both content- and context-appropriate". Internationally, the DNLA note the importance of teaching students "in authentic and meaningful ways within the context of learning in other subject areas" (Skov \& Skærbak, 2003, 327). Hegarty and Carbery $(2010,610)$ note how Waterford Institute of Technology (WIT) address low attendance at non-compulsory classes, and issues of information overload which present themselves at the information desk, with embedded classes that direct nursing students "toward independent learning through active learning techniques".

As in WIT, the growing prominence of IL is shown to have consequences for a broad range of library staff. Kavanagh $(2009,13)$ demonstrates that, as subject librarians in DIT undertake studies such as teaching qualifications, there is a knock-on effect for library assistants who are "trained to handle more information queries”. Internationally, Hauxwell $(2008,92)$ notes that empowering paraprofessional staff can support informal IL interventions by offering "tailored, relevant snippets of IL training" at the library desk; such "contextualised interaction at the point of need" may be more effective than formal teaching. As such, continuing professional development (CPD) is an important emerging issue for library staff. Bury $(2010,2)$ recognises that "the value of CPD is overwhelmingly acknowledged as important" in her survey of CPD and Irish libraries. The lack of a national strategic policy, such as CILIP's chartership and fellowship programmes, means that Ireland does not have a "structured route to formal and broad-base recognition of CPD activities and accomplishments" (Bury, 2010, 2).

However, less formal programmes do exist. For instance, introductory courses on academic writing for library staff are facilitated by Helen Fallon, of the National University of Ireland Maynooth. Such initiatives help to transform the "wealth of knowledge, skills and experience" of Irish practitioners into published material (Fallon, 2009, 414). Smith and Harvey $(2006,616)$, too, assert that "a strong research culture is considered essential to any mature profession". Thus, issues arising in the Irish and international literature have very strong parallels.

\section{Methodology}

\subsection{Project approach}

Qualitative methods of research, set in a modified Delphi methodology, were used in this study. Developed at the RAND Corporation by researcher Olaf Helmer in 1967, the original form of the Delphi methodology involves eliciting opinions from experts, in a given field, by means of multiple rounds of surveys; each round 
feeds the collected data and opinion from all of the experts in to the next round until a convergence of the study participants' opinion is reached. As each round is carried out participants have the option to change or alter their opinion.

This research method was chosen as the "Delphi technique is a procedure for structuring the communication process of a group, to allow a group of individuals, as a whole, to deal with a complex problem" (Wen and Shih, 2008, 792). This research technique is designed to "elicit information and judgements from participants to facilitate problem-solving, planning, and decision-making" (Wen and Shih, 2008, 792), and is a "recognised instrument to make predictions and help decision-making" (Landeta, 2006, 468), which are important factors in the research of IL practice both nationally and internationally. The research team decided to use Delphi methods modified for the purposes of other study, as "in practice, the Delphi technique is always adapted to the requirements and goals of the project in question" (Wilenius and Tirkkonen, 1997, 849).

\subsection{Research design}

In order to add value to existing research, and to make practical recommendations to TFIL, the research team conducted an international study of the leaders in the field of IL as well as revisiting the original Irish case studies. In order to develop best practice in Ireland, a good understanding of the national and international contexts were deemed to be not just important, but necessary. The research design included both Irish and international study participants and was carried out in two phases: (1) an interview stage and (2) a survey stage.

\subsection{Sample}

The research sample for the study included 9 international experts and 17 Irish experts. In total 26 interviews were undertaken and 16 surveys were returned for analysis.

\subsection{Data collection}

There were two stages of data collection in the research design: (1) the interview stage and (2) the survey distribution. As per the Delphi methodology, findings from the interview stage were collected and synthesised to inform the survey.

The project was conducted over a six-month time frame. The initial review of the literature was conduct over the first two months, March and April; the interview stage of the research design, was conducted in May, June and early July; with the survey stage of the research being conducted in July and early August.

\subsubsection{Stage one: the interview stage}

The research team conducted semi-structured interviews with representatives of international organisations using the computer software, Skype; face-to-face interviews were held to revisit national case studies. Using the Delphi methodology suited the inclusion of international experts: "Delphi is desirable in 
that it does not require the experts to meet physically" which is "impractical for international experts" (Okoli and Pawlowski, 2004, 18).

Once the interviewing stage of the research was completed, inductive and deductive methods were used to code interviews. A second round of coding, including cross-coding, was conducted and, once the coding was completed, common themes emerged.

\subsubsection{Stage two: the survey stage}

The second stage of the research design was the distribution of a survey which synthesised the main views of interview participants, including themes such as advocacy, training, research, etc. The surveys were distributed with a fixed deadline. The online computer software, SurveyGizmo, was used to distribute and collect the survey. Prior to distribution, the survey was tested by two librarians and their feedback was incorporated into the design. Scales were used to highlight the importance of certain recommendations or initiatives regarding IL practice both in Ireland and abroad. This aspect of the Delphi approach allows for experts to express their views on their peers' thoughts, to observe their views and to give feedback.

A further inductive and deductive coding session was undertaken of collected survey data, similar to the coding of the interview data; the combined identified themes from the interview and survey data were used to structure the discussion of the research's findings on IL practice in Ireland and abroad.

\section{Findings}

For this article we will concentrate on our Irish findings. As in the international context, the Irish IL landscape was found to be constantly shifting. Each of the libraries in the WGIL case studies had altered their practices since 2008. Apart from one, the libraries had all progressed with their programmes and built on the work described in their case studies. The recession had certainly taken its toll with the availability of both resources and staff; however, the majority of experts interviewed do still prioritise IL. There was one notable exception where staff changes and financial issues meant that IL was no longer a priority. The main themes that emerged included the importance of embedding IL programmes in the educational curriculum, supporting lifelong learning and e-citizenship, the importance of IL in the workplace, continuing professional development and advocacy.

\subsection{Importance of embedding IL programmes in the curriculum}

One of the major themes to emerge from the findings in the report is the importance of embedding IL programmes across the curriculum: from national and secondary schools to third level education. Academic libraries are now designing and delivering tailored workshops and lectures in collaboration with academic staff, and ensuring that the specific module learning outcomes of individual lecturers are met. Practitioners revealed that learning objects and 
outcomes relating to IL are met by ensuring most of the teaching given by library staff is embedded in the module. The research showed that educational institutions have developed a range of online resources, for instance library staff delivering lectures online in real-time using Wimba / Blackboard; these initiatives are helping to make IL programmes more sustainable.

The importance of embedding of IL instruction in the curriculum was illustrated by University College Dublin's decision to introduce a new module for September 2013 called Digital Judgement: Truth, Lies and the Internet; the module expands upon previous modules by including digital information in all of its formats, looking at how to evaluate and find trustworthy information online and understanding digital footprints. In contrast, the research also revealed that the recession has led one academic library to switch their focus from embedding IL into each post-graduate programme to creating a generic IL course for all postgraduate students. Staff share teaching responsibilities on the generic module, freeing up the time to dedicate to individual students for one-to-one subjectspecific assistance.

IL is also growing at second-level, with one private school library continuing to support a fully sustainable IL programme which appears to have been unaffected by the recession. The school's policy places a lot of importance on supporting and promoting IL and this is evident from the scope and range of IL sessions delivered to the students. IL classes given to the students can range from how to locate and become familiar with the library (1st year students) to being shown how to conduct subject research skills (6th year students). However, it should be stressed that this example of best practice is not the norm in Irish secondary schools.

\subsection{Supporting lifelong learning and e-citizenship}

The growing importance of independent, lifelong learning was a strong crosssectoral theme. The role of public libraries in the provision of information literacy services to Irish citizens is evolving.

In recent years, state agencies have increasingly made state services available online; some such services can only be accessed online. The marginalisation of vulnerable groups has become more evident. Librarians also note a shift in public expectations; in addition to logistical queries, patrons are increasingly seeking assistance with the content of the online forms that they are completing. Most library staff are not currently qualified to meet the need for such advice.

Practitioners suggest expanding and formalising this role by, for instance, incorporating a Citizens' Information Desk into some public libraries. Such a development could designate the library as a first port of call for informed citizens and relieve some of the pressure on local government departments. In addition, one of our experts asked that TFIL support practitioners by devising a policy statement for public library staff who endeavour to provide more than logistical assistance to patrons who wish to avail themselves of online state services. 
As well as e-citizenship, public libraries are meeting patron needs by providing lifelong learning opportunities. Patron-centred courses include computing classes for the elderly and teaching parents about online gaming. One library, aware of the lack of a third level college in their county, collaborated with local educational institutions and the FÁS (Foras Áiseanna Saothair - Training and Employment Authority) e-learning college to provide opportunities for continued learning. They also devised a FETAC level-5 "library skills" course (L22475) to make information skills available to those outside the formal education sector.

\subsection{IL in the workplace}

IL services for patrons outside of the formal education sector are, undoubtedly, growing but evidence of workplace IL is not as prevalent in the Irish context as it is in the international context. However, the anticipated importance of IL in the Irish workplace was evident in one of the recommendations of the WGIL Report: to "promote the inclusion of IL in education at all levels and in workplace staff training and development - not least amongst library staff themselves" (Working Group on Information Literacy, 2008).

The challenges of implementing IL in the workplace can be seen in one busy university hospital library. As a teaching hospital, it encompasses both educational and professional environments. Prior to the economic recession, this library reported plans to implement IL training programmes that would facilitate the use of the library materials by staff and students; existing programmes were given positive feedback from participants. Unfortunately, due to budget constraints and library staff shortages, formalised IL programmes were suspended indefinitely with no foreseen reinstatement. IL is no longer part of the library's strategic plan although one-to-one training is still provided. A shift in focus, probably influenced by the recession, sees the expertise and professionalism of the library staff increasingly promoted in this organisation.

Elsewhere, staff at the network of Citizens' Information Centres (CIC) are active lifelong learners. All information workers must undertake an accredited FETAC level- 6 qualification, which is offered by the National College of Ireland. Some CIC staff are returning to education as adults and require assistance with features of their studies such as online learning modules and independent study.

Work-based IL provision was also evident in the professional sector. One expert noted the need to provide support to a broad range of legal practitioners; varying levels of expertise, interest and time influence the degree to which these practitioners want to become independent learners and the degree to which they delegate information-seeking tasks. Library staff who work alone, in support of workplace IL, may need support from practitioners in other organisations; for instance, while our expert has in-depth knowledge of the resources available, she would welcome pedagogical training in order to deliver this information as effectively as possible. 


\subsection{Developing continued professional development}

In addition to supporting IL initiatives in Irish workplaces, a recurrent theme was the importance of supporting continued professional development (CPD) among library staff themselves (Figure 1). The research found that CPD was a strong theme in the Irish findings, with experts and practitioners strongly encouraging it where it existed, for example in the academic library sector, and calling for it where it did not exist, for example in the school library sector.

Within one academic institution, staff were encouraged to become researchers in order to provide solid evidence to back up the importance of IL policies and services. A LIS lecturer also confirmed this trend and encouraged the submission of papers by librarians to journals other than library related journals such as health, the sciences and law, in order to promote themselves and IL.

Interestingly, librarians are now seizing the initiative for themselves and enrolling in third-level diplomas in teaching and learning as they are "often thrown in at the deep end with regard to teaching". Comments suggest that going forward, it is important for librarians to build up a 'skills portfolio' and to provide added value as librarians.

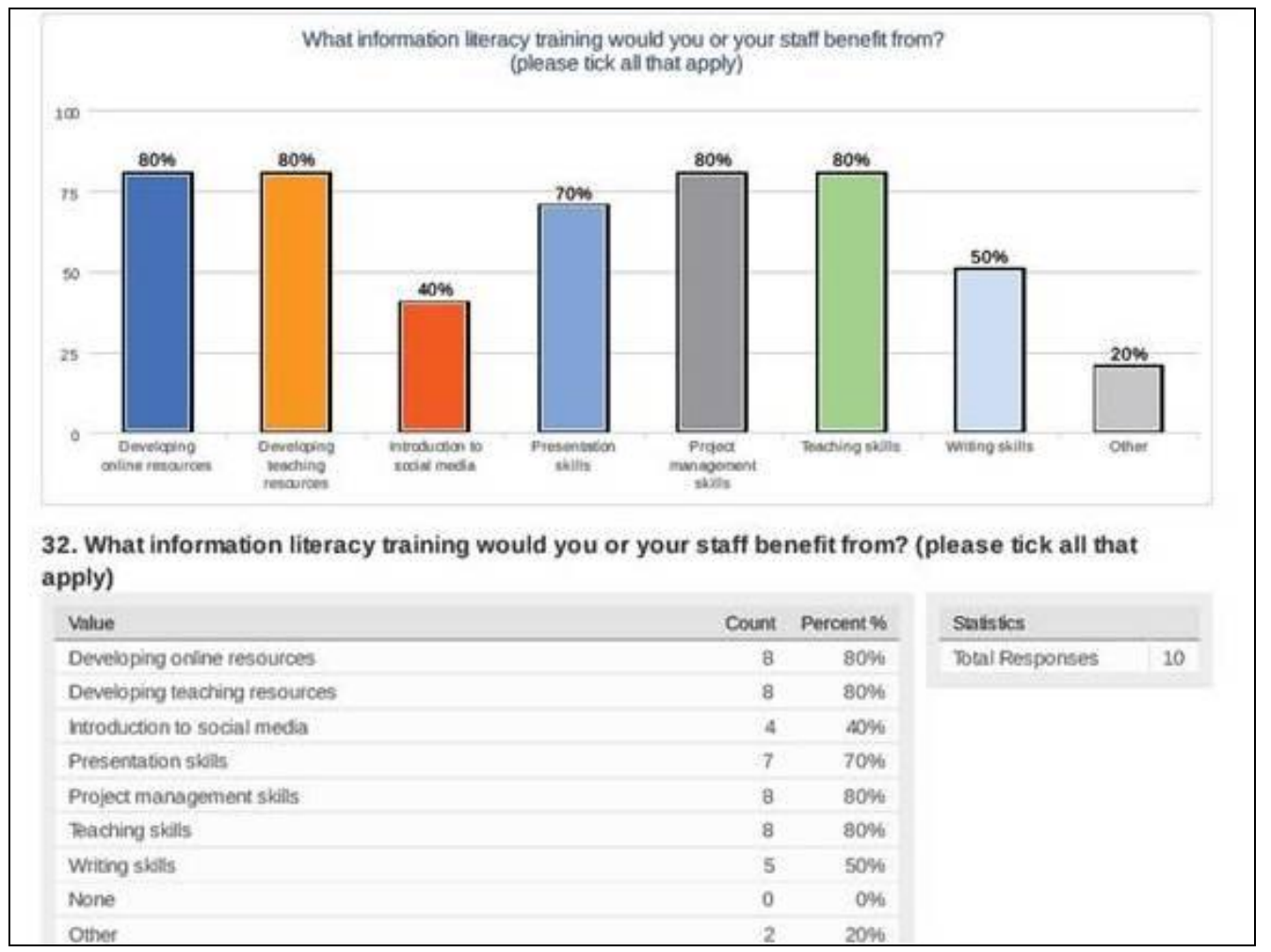

Figure 1: Continuing Professional Development Training

\subsubsection{Training librarians how to teach}

Within the CPD findings, a strong sub-theme emerged, one less apparent in our international findings; there is a need to address the issue of training librarians 
how to teach, with additional calls to anchor the teaching of IL to librarians during their formal education.

There were calls for the curriculum for trainee librarians to be reformed emphasizing the need to equip librarians with teaching techniques, including being able to work with groups, to understand group needs, targeted learning and focussing more on learning outcomes. A "one-size fits all" approach is no longer deemed to be sufficient for IL practitioners.

\subsubsection{Flexible CPD learning and online resources}

Our experts cited the following factors as necessary to facilitate CPD: recognition from management, time to attend conferences and training, time for reflection, sufficient staff, and the support to develop online resources. Many academic practitioners commented that it can be difficult for staff to learn and to work simultaneously. There is great scope for offering library staff flexible learning and current awareness opportunities, and for providing them with appropriate online and face-to-face tutorials which recognise their needs and constraints. When this issue was followed up, survey respondents commented that they would like "regularly updated online tutorials, informal group meetings, such as TeachMeets". The creation of a centralised online Irish IL resource was considered a welcome initiative by practitioners; it would provide "a core body of information, and re-useable learning resources". Experts were positive about the possibility of participation by their colleagues. Such online forums would support communication and foster dialogue among library staff regarding current IL practice at their institution and facilitate the free exchange of IL initiatives.

\subsection{Advocacy}

Parallel to a desire for CPD among our experts, a need to generate advocacy and support IL champions was evident. There was a clear recognition of the need to advocate within the profession in order to spread awareness of the role and importance of IL among those who would provide the service. Nationally, the research survey revealed this strongly with $90 \%$ of respondents stating that they felt it was very important to advocate for IL.

In order to train, support, embed and promote IL, advocacy, both within and outside of the profession, was seen as essential. Our survey revealed this with $90 \%$ of respondents stating that they felt it was very important to advocate for IL (Figure 2). The School Library Association of Ireland (SLARI) reported the need to lobby and advocate on their behalf as "we live in an instant information society" and this needs to incorporated into learning in the future, adding that libraries and IL can play a huge role in this.

The areas of promoting standards, best practice and in particular the area of evaluation were highlighted as key areas of concern nationally. A public library expert suggested that if TFIL:

could work at the top of the pyramid and inform us of the best practice that would be useful, to collate the different information being produced by different agencies 
and organisations and promote to practitioners how it could be made applicable in other environments.

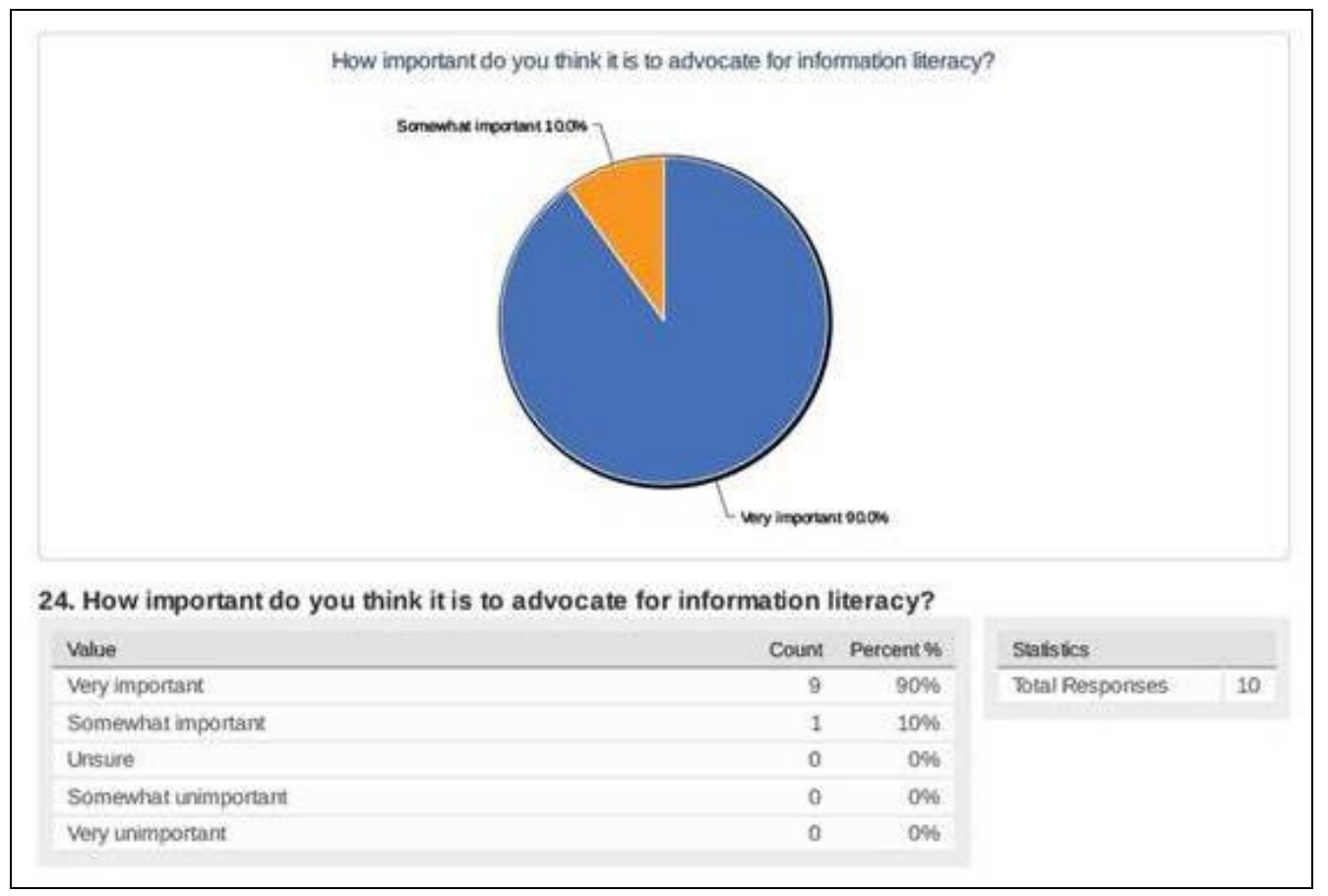

Figure 2: Importance of advocating for information literacy

$90 \%$ of survey respondents believed that library managers were best placed to advocate on behalf of the profession. For example, according to one respondent to the Irish survey, "the voices of library managers are taken more seriously at governmental funding level than the voices of other staff members". This does not necessarily mean that managers are more skilled in IL than other library staff or IL practitioners. It does, however, mean that it is critical for libraries to be seen as the primary patrons of IL, while open to assistance in a secondary role from other sectors. Such high-level advocacy would play an important role in supporting practitioners, within the profession, and colleagues, outside the profession.

The research in our study revealed that there was an understanding that IL exists both within and outside of the profession and this brought with it recognition that IL could be split into two strands, external (from the profession) and internal (for the profession). Both approaches are needed as each on its own would not be sufficient to achieve the increased levels of advocacy currently required. There was a consensus that that there should be a unified message and that the principles for promoting IL are the same for the information profession and those who operate outside it. Experts conceded that a problem in the past has been the nearexclusive association of IL with the information profession:

to overcome this, it will be important to show that IL is a universal concept, and not just the preserve of information experts. Having said that, there is perhaps more work involved in demonstrating the importance of information/digital literacy to other sectors. 
As such, our findings concern themselves with both practical and strategic aspects of IL development in Ireland. While individual practitioners repeatedly show excellence in their day-to-day activities, there is scope for an overarching strategy and communication forum to share these developments.

\section{Recommendations}

Based on the findings of this research, it is clear that a practical set of recommendations are necessary. A two-tiered approach is proposed (Figure 3): (1) a high-level advocacy committee and (2) a practitioner-led community of practice. Building an effective tool, which would support such a two-tiered IL community, would require the inclusion of both online and offline components.

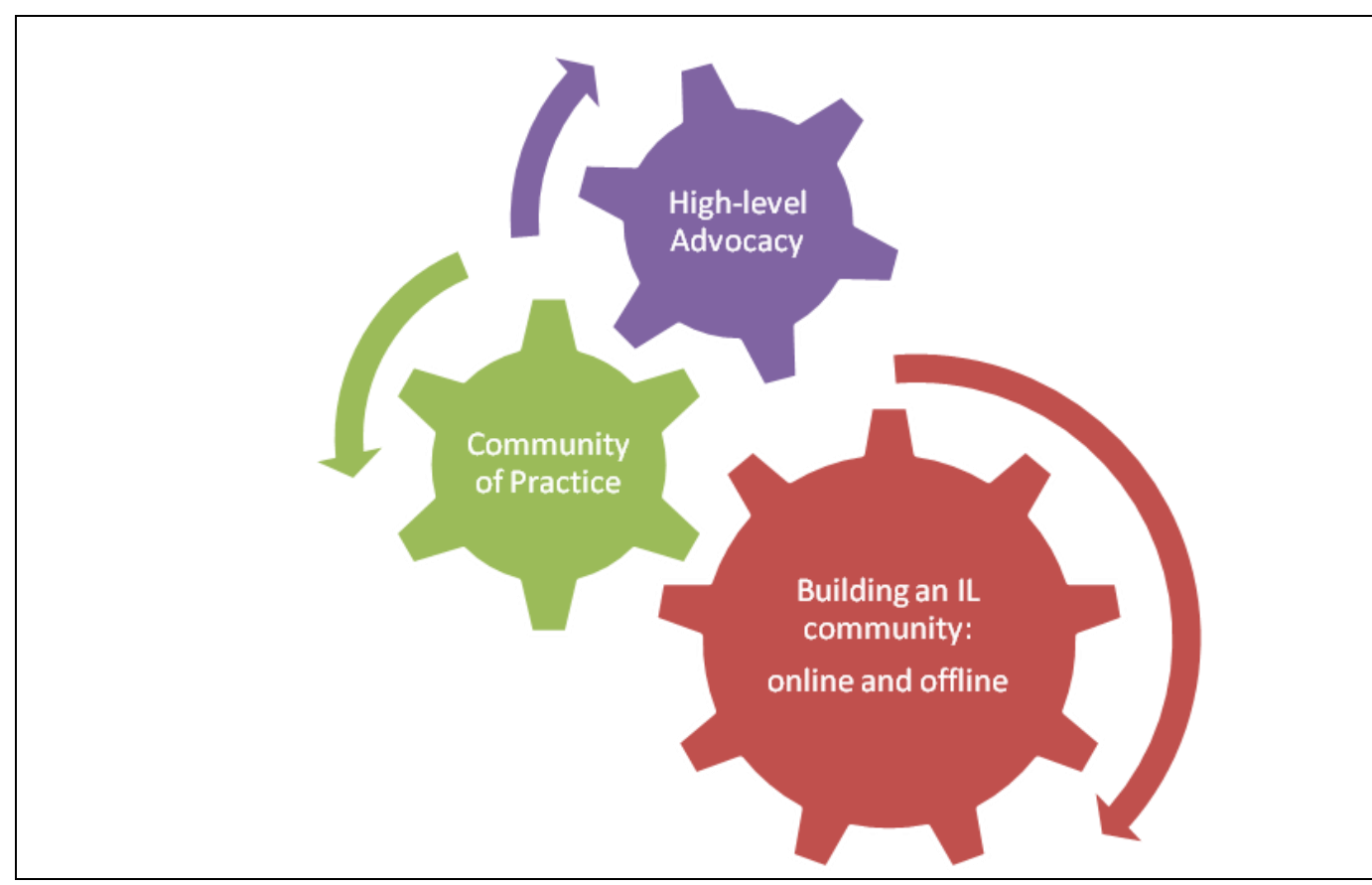

Figure 3: Two-tiered recommendation: high-level advocacy and community of practice

\subsection{Building an IL community}

At the heart of this proposal is the importance of building an IL community in Ireland; this community would have both online and offline components in order to meet the preferences and harness the needs of the entire practitioner community (Figure 4).

\subsubsection{An online IL community}

The provision of one authoritative, centralised online resource for IL practice in Ireland emerged as a strong recommendation in the findings. A precedent has been set for excellence in this area by the CILIP IL Special Interest Group 
(Information Literacy, 2005); in fact, it is evident that their website is also used by many Irish practitioners.

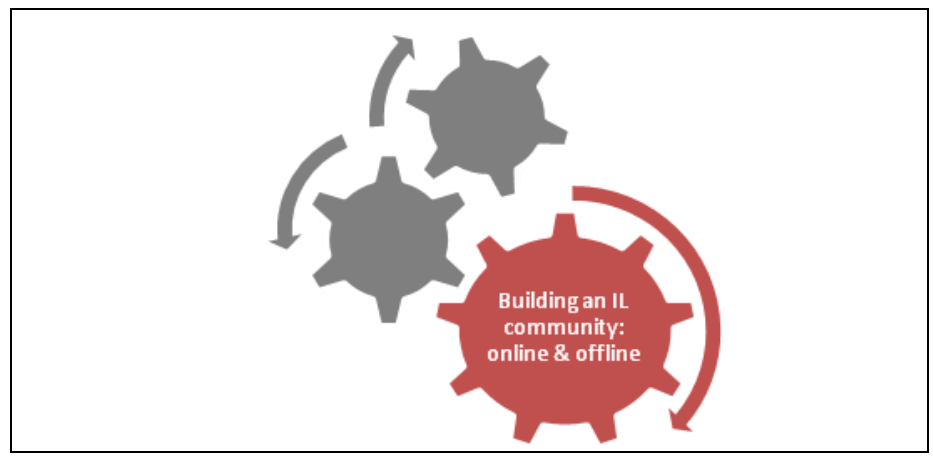

Figure 4: Building an information literacy community online and offline

A focal point for all aspects of IL practice, an Irish online community would support each of the two tiers, i.e. (1) high-level advocacy and (2) a community of practice, on which the recommendations are based.

The advantages of hosting such a community online include increased accessibility to resources, a repository of IL literature, an opportunity for networking and sharing knowledge, an opportunity to communicate with peers, and a greater sense of inclusion for practitioners in small or remote organisations. Hosting this community on a wiki would facilitate active participation by a wide range of participants and reduce the administrative requirements on individuals.

\subsubsection{An in-person IL community}

There is a strong tradition of in-person community building in the Irish library community. Committees, seminars, TeachMeets etc. provide opportunities for practitioners to come together physically and to share opinions and experiences.

The findings of this research indicate the potential for a stronger sense of regionalisation in the Irish IL community. A key recommendation of this report is to consider the possibility of creating 3-4 regional networks outside the Dublin area, for the purposes of supporting local information literacy communities. It is envisioned that such regional groups, championed by local library staff, could provide invaluable cross-sector, peer support. At present, most in-person information literacy events are Dublin-centric and this often makes them inaccessible for practitioners in other parts of the country. Regional groups could also work together effectively to provide a holistic cross-sector service to their communities and reduce duplication where possible. A successful precedent for such regional groups has been established in South County Dublin.

\subsection{A two-tier approach}

A two-tiered approach is recommended because of the variety of skills and expertise in the Irish IL community. The findings demonstrate clear evidence of the success of two core groups within the community: (1) high level strategists 
and managers, such as the members of WGIL and (2) innovative practitioners who plan and implement IL programmes throughout Irish libraries.

- Tier 1: high-level advocacy;

- Tier 2: community of practice (Figure 5).

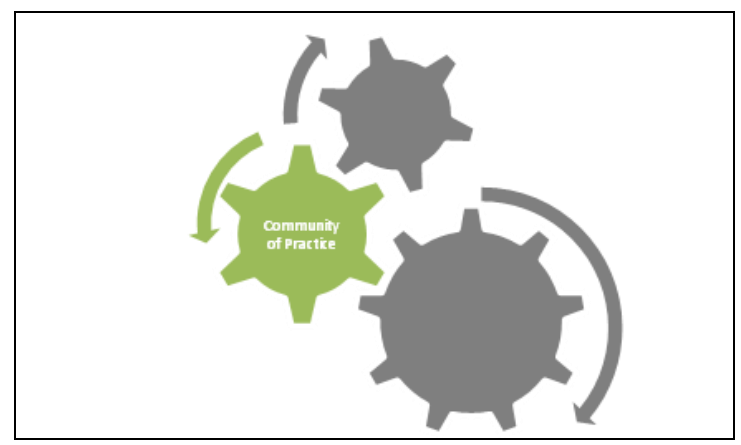

Figure 5: Tier 2 Community of Practice

\subsubsection{Tier 2: a community of practice}

Our neighbours in the UK, including the CILIP Special Interest Group and the Scottish Information Literacy Project, have set a precedent in excellence in establishing communities of practice. Both use online resources, and in-person meetings, to build IL practice.

Our report recommends that the primary role of TFIL, in the community of practice, should be one of facilitation. TFIL can empower practitioners to innovate, collaborate and grow by providing the resources and policies to support the online and in-person components of the community of practice.

Three primary areas form the basis of the community of practice: research, collaboration and continuing professional development.

\subsubsection{Research}

A healthy research environment is a core component of any innovative and evolving area of expertise. Traditionally, library staff have not always considered themselves to be researchers or academics; this is clearly changing. A range of new opportunities are beginning to be made available, such as courses teaching librarians to publish at NUI Maynooth and opportunities for auditing SILS modules at UCD (Table 1).

\subsubsection{Collaboration}

One of the core recommendations of the WGIL Report was to co-ordinate IL activity across the library sectors; the findings of this report reiterate that. There is a lot of scope for collaboration and the co-ordination of activity in Ireland, as many libraries are meeting the needs of similar communities. There is a strong feeling that "reinventing the wheel" is a luxury that Irish practitioners no longer have the time or resources to do (Table 2). 


\subsubsection{Continuing professional development (CPD)}

Interviews, surveys, anecdotal evidence and the literature all point to an aspiration for continuing professional development among IL practitioners, both in Ireland and overseas. As the need for IL becomes more prominent among library patrons, a broader spectrum of library staff are expected to meet this need (Table 3).

\begin{tabular}{|c|c|}
\hline \multicolumn{2}{|c|}{ Research } \\
\hline Community & Virtual community \\
\hline $\begin{array}{l}\text { (1) Development of regional support } \\
\text { - Skills portfolio development } \\
\text { - Introductory courses to publishing } \\
\text { - Collection of local knowledge re. research resources } \\
\text { (2) Activities based at key locations } \\
\text { - Translating a thesis into an article (e.g. at UCD SILS) } \\
\text { - Occasional courses on research methods (e.g. at UCD SILS) } \\
\text { - Sector-specific research courses (e.g. in a health library) } \\
\text { (3) Activity-specific events } \\
\text { - Organising a national IL conference for Ireland } \\
\text { - Publishing an Irish journal of IL } \\
\text { - Sponsoring a prize for innovation in IL practice }\end{array}$ & $\begin{array}{l}\text { (1) Central online resource: data collection } \\
\text { - Database of research resources } \\
\text { - Repository of research articles } \\
\text { - Repository of case studies } \\
\text { - Access to databases (potential) } \\
\text { (2) Central online resource: collaborative space } \\
\text { - Skills portfolio development } \\
\text { - Introductory courses to publishing } \\
\text { - Contact details for Irish practitioners } \\
\text { - Online discussion list or forum } \\
\text { (3) Activity-specific events } \\
\text { - Organising a national e-conference or online seminar } \\
\text { - Publishing an Irish e- journal of IL }\end{array}$ \\
\hline
\end{tabular}

Table 1: Recommendations for research

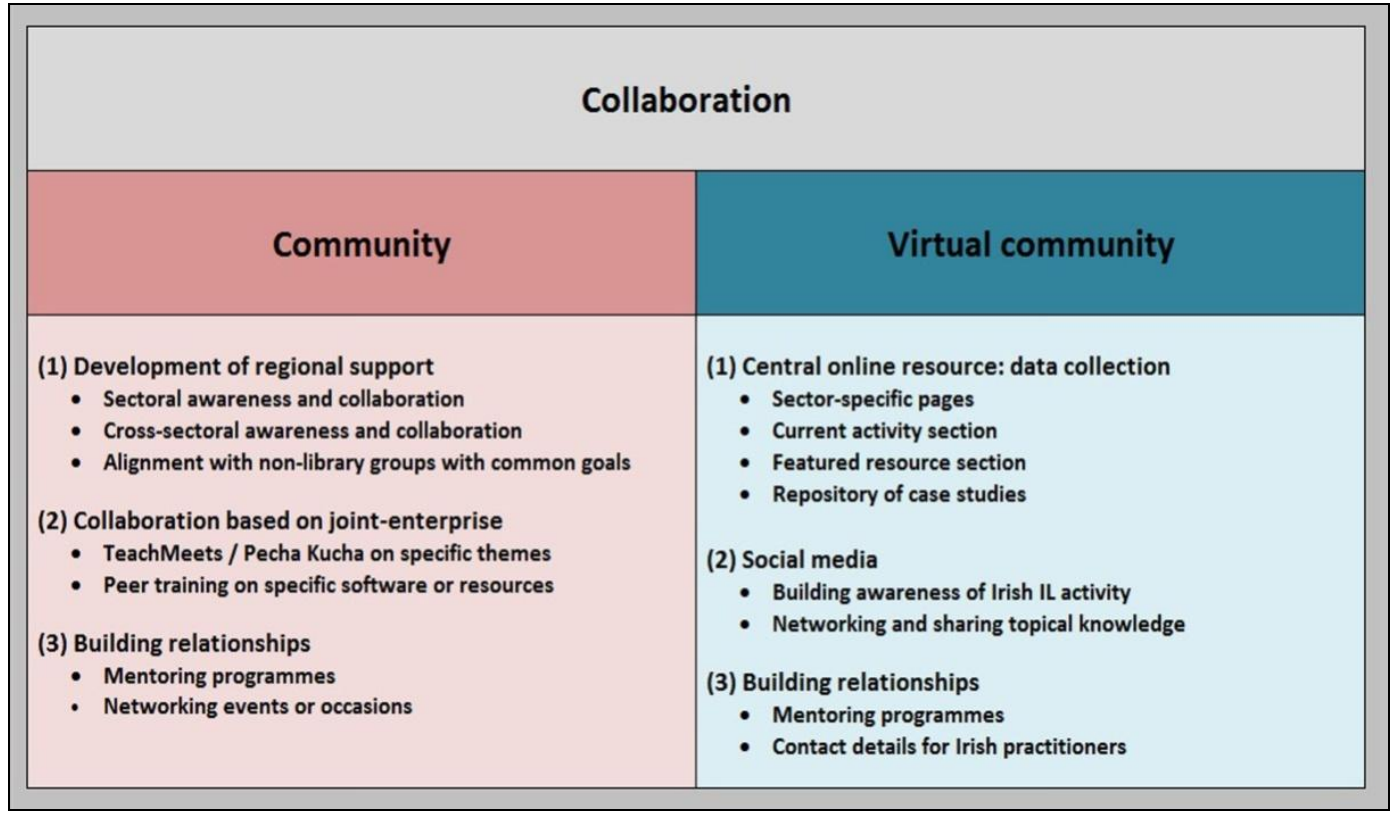

Table 2: Recommendations for collaboration 


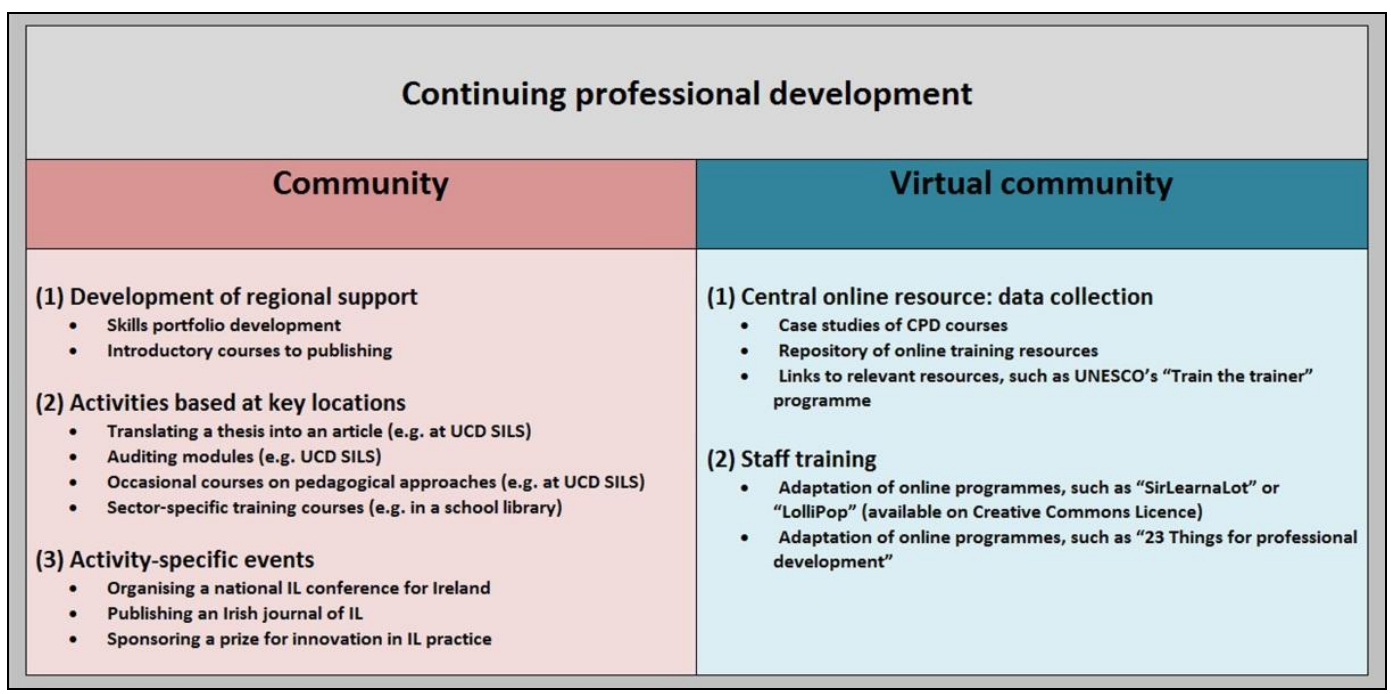

Table 3: Recommendations for continuing professional development

\subsubsection{Tier 1: a high-level advocacy committee}

From the findings of this report, it became clear that strategic advocacy is required in order to promote the importance of information literacy in Ireland. While practitioners implement IL programmes at a local level, there is a need for an overarching strategic body to take a more holistic national approach to advocating for information literacy (Figure 6). Such advocacy would take place within the library profession, but to a greater degree outside of the profession.

Within the library profession, a high-level advocacy committee would provide a framework that supports and facilitates the work of the community of practice. As outlined in the findings, for instance, some of our experts suggested the need to draft policies in relation to certain aspects of information literacy and to facilitate the synthesis of IL data across the Irish library sectors.

Outside the library profession, a high-level advocacy committee would liaise with other national library organisations, collaborate with non-library groups whose information literacy goals are aligned with those of libraries, and lobby local and national government agencies to support information literacy initiatives across public life. It is vital that strategists and managers have a broader perspective than local practitioners, and that they concern themselves with promoting the interests of information literacy in wider society.

A high-level advocacy committee would enable information literacy to establish a sound footing in strategic plans within the Irish library community and within other organisations that share information literacy goals. 


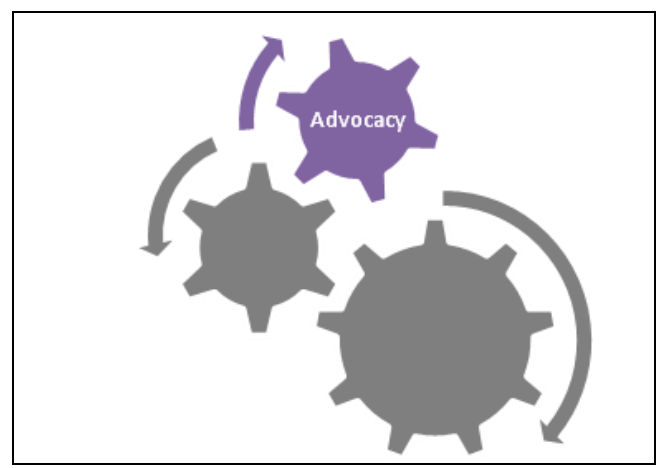

Figure 6: Tier 1 Advocacy

\section{Conclusion}

In conclusion, the project covered a fascinating period in the development of information literacy in Ireland. Inspired by colleagues overseas, particularly in UK, the research found that the Irish IL community has the potential to harness existing innovation among practitioners; this will help to create a sustainable community of practice which will inform innovation both within and beyond the library profession. Furthermore, the establishment of a high-level advocacy group will foster the holistic nature of IL and lead the recognition of information literacy and its integration in the wider society.

Building Information Literacy in Ireland is a complex and long-term goal, but the pioneering work of WGIL and TFIL presents a real opportunity for success.

\section{References}

Abromeit, K.A. and Vaughan, V. (2004) Info Lit and the Diva: Integrating Information Literacy into the Oberlin Conservatory of Music Opera Theatre Department, Notes, 60(3), 632-652.

Bury, S. (2010) Continuing Professional Development and Irish Libraries: Report of Key Survey Findings. URL: http://www.ucd.ie/t4cms/sils-cpd-execsummary.pdf [accessed on 22.08.12].

Dunne, S. (2008) Collaboration on a grand scale: facilitating the transition of firstyear students into higher education, SCONUL Focus, (44), 19-21.

Fallon, H. (2009) A writing support programme for Irish academic librarians, Library Review, 58(6), 414-422.

Hauxwell, H. (2008) Information literacy at the Service Desk: the role of circulations staff in promoting information literacy, Journal of Information Literacy, 2(2), 86-93. 
Hegarty, N. and Carbery, A. (2010) Piloting a dedicated information literacy programme for nursing students at Waterford Institute of Technology libraries, Library Review, 59(8), 606-614.

Information Literacy (2005) Information Literacy. URL:

http://www.informationliteracy.org.uk [accessed on 22.08.12].

Kakkonen, A. and Virrankoski, A. (2010) Implementation of the Finnish University Libraries National Information Literacy Recommendation into academic studies at the Kumpula Science Library, University of Helsinki, New Library World, 111(11), 493-502.

Kavanagh, A. (2009) Changing times: the changing role of assistant librarians in DIT's Aungier St library, SCONUL Focus, (45), 12-15.

Landeta, J. (2006) Current validity of the Delphi method in social sciences, Technological forecasting and social change, (73), 467-482.

O'Brien, T., and Russell, P. (2007) The Irish Working Group on Information Literacy: edging towards a national policy, SCONUL Focus, (41), 26-30.

Okoli, C. and Pawlowski, S.D. (2004) The Delphi method as a research tool: an example, design considerations and applications. Information and Management, (42), 15-29.

Skov, A. and Skaerbak, H. (2003) Fighting an uphill battle: teaching information literacy in Danish institutions of higher education. Library Review, 52(7), 326332.

Smith, K. and Harvey, R. (2006) Is there a role for professional associations in fostering research? In: C. Khoo, D. Singh \& A.S. Chaudhry (eds.), Proceedings of the Asia-Pacific Conference on Library \& Information Education \& Practice 2006 (A-LIEP 2006), Singapore, 3-6 April 2006. Singapore: School of Communication \& Information, Nanyang Technological University. 612-619.

Wen, J.R. and Shih, W.L. (2008) Exploring the information literacy competence standards for elementary and high school teachers. Computers and Education, (50), 787-806.

Wilenius, M. and Tirkkonen, J. (1997) Climate change in the making: using Delphi for Finnish climate policy. Futures (29), 845-862.

Working Group on Information Literacy (2008) Review of Cross-sector Activity 2006 to 2008 and Initial Recommendations for Further Action [unpublished material]. 


\section{The Occasion}

This paper was written to accompany the Masters Capstone Project, entitled BILI: building information literacy in Ireland, which follows on from the Report of the LAI Working Group on Information Literacy.

\section{Open access and copyright}

Library and Information Research is an open access journal. A freely available copy of this paper may be downloaded from the journal's website:

http://www.cilipjournals.org.uk/lir

Copyright and associated moral rights in works published in Library and Information Research are retained by the author(s) but this paper may be used freely, with proper attribution, in educational and other non-commercial settings. 